\title{
Editorial: A New Public Understanding About Addiction
}

\author{
Ilana Crome, MD, FRCPsych, ${ }^{1}$
}

A. Thomas McLellan, $\mathrm{PhD}^{2}$

Recommended Citation: Crome I, McLellan AT. Editorial: A New Public Understanding About Addiction. Public Health Reviews. 2014;35: epub ahead of print.

\section{BACKGROUND AND CONTEXT}

\section{Substance Use Disorders' Effects on Mainstream Healthcare}

Substance use disorders-defined here as harmful use of cigarettes, alcohol, illicit and non-prescribed licit drugs-affect approximately 20 percent of adult populations in most western countries. ${ }^{1}$ In the United States, approximately eight to ten percent of the adult population ${ }^{2}$ have the most serious form of this disorder- "addiction". An additional 40 million adults use substances in a manner that significantly interferes with their health and healthcare. ${ }^{3}$ Yet screening, intervening and treating substance use disorders have not been embraced within mainstream healthcare or by most public health initiatives.

The impact of the US Surgeon General's 1964 report on smoking is a case in point. ${ }^{4}$ This report was an important impetus, eventually demonstrating that multiple modes of prevention and treatment intervention resulted in dramatic reduction in smoking in the US and elsewhere, which in turn contributed to reduced death rates from cardiovascular diseases and lung cancer especially. ${ }^{5,6}$

As regards other substance abuse, especially illegal drugs, it may be thought that the inattention from public health and healthcare providers results from a lack of effective medications, therapies or interventions to

\footnotetext{
${ }^{1}$ Keele University and South Staffordshire and Shropshire Healthcare NHS Foundation Trust, Stafford, ST16 3SR, UK.

${ }^{2}$ The Treatment Research Institute, 600 Public Ledger Bld., 150 S. Independence Mall, Philadelphia, PA 19106, USA.
} 
address substance use problems. This is not the case. If we accept the US Food and Drug Administration standards for judging effectiveness (effectiveness in two randomized controlled trials or one large-scale field trial) there are at least three screening instruments, five prevention interventions, five medications and over a dozen behavioral therapies that can be called effective in identifying, intervening early and treating/managing substance use disorders. ${ }^{7}$

Whether benign inattention or wilful neglect, failure to address substance use problems as a public health issue has been an expensive mistake. In the US, these disorders produce annual costs of over USD $\$ 120$ billion in unnecessary or inappropriate healthcare procedures, inaccurate diagnoses, poor treatment adherence and rapid re-hospitalizations. ${ }^{8-10}$

Internationally, although there is great variation in the types and quantities of substances consumed, the problems are overwhelming. Notwithstanding the considerable difficulties in generating reliably comparable estimates worldwide, approximately one in three adults use tobacco, equating to one billion people. ${ }^{11}$ Despite reduction in smoking in high income countries, tobacco and alcohol consumption are the fourth and fifth most important risk factors respectively for global burden of disease. ${ }^{12}$ If current trends continue, tobacco use will kill 100 million people prematurely during this century. ${ }^{13}$ The United Nations estimated that in 2007 between 172-250 million people took drugs at least once in the previous 12 months and that five percent of the population between the age of 15-64 years had used drugs at least once in the previous 12 months. ${ }^{14,15}$

Responses to these harrowing conditions are diverse and imaginative, despite the limitations of covert obstacles and overt lack of resources, and this might explain why only a small proportion of cases have contact with treatment services within the first year of onset of a substance misuse disorder; the proportion in the developing world is lower than that in the developed world. ${ }^{16}$ As will be described, much of the exciting and rapidly accumulating translational research has been generated in the developed world. In order to minimise the gap between need, demand and availability, we recognize the pressing need to cautiously and humbly examine whether the impact could be transferable, or whether other models may be more appropriate at this point in time. ${ }^{17}$

\section{Change is Imminent}

Among the many reasons explaining the lack of attention to substance misuse within the healthcare field is the longstanding public conception that addiction is a sin, a sign of weak character, or a bad habit—not a health condition. ${ }^{18}$ 
But powerful forces have combined over the past decade to change public opinion and with it, the public approach to substance misuse and addiction.

The first of these forces of change is the accumulating basic and clinical research findings about the nature of addiction. Especially in the last two decades, research in genetics and brain imaging has revealed that substance use can trigger a complex series of gene expressions and produce significant, prolonged changes in brain reward, cognition, inhibition and motivation circuits. In turn, these prolonged brain changes help explain one of the most perplexing and frustrating aspects of addiction-the enduring loss of control to resist or to moderate alcohol and other drug use. ${ }^{19}$ While these biological findings leave open the important questions of personal responsibility, they make clear why usually powerful societal means of behavioral control such as family role, social norms, laws and punishments have so often failed to be effective in controlling addiction behaviors. These will provide new methods of health promotion intervention that may help to alleviate the global pandemic of substance abuse.

Epidemiological, prevention and health services research findings have also contributed importantly to an emerging new public understanding about substance misuse and addiction. Population research on the etiology of addiction suggests that virtually all addictions have an "at risk" period that roughly corresponds to adolescence. Specifically, addictions are much more likely among those who begin use at or below the age of 15 . In contrast, those who do not show evidence of addiction by their early twenties have very low rates of subsequent addiction. There are of course many potential reasons to explain these findings but prominent among them are the powerful effects that substances of abuse can have on the developing adolescent brain. Because the initiation and escalation of substance use and misuse are so likely and so dangerous during adolescence; and because it is now possible to screen and effectively intervene to halt or reduce emerging substance use, it is clear that innovative prevention and early intervention strategies are an important public health complement to treatment approaches - particularly for adolescents. At the other end of the age and substance use spectra, there has been increasing awareness of the impact of alcohol and other drug misuse by older people. The nature and patterns of substance misuse among this large population segment are also of concern for the healthcare field as substance misuse problems often interact with the many chronic health problems associated with ageing, complicating diagnosis, management of the disorders themselves and can produce potentially lethal interactions with prescribed medications. Since it is likely that the number of older substance misusers needing treatment could triple by 2020, this is an area requiring further understanding. 
The third force for imminent change in this area is the emergence of popular demand for new political, organizational and clinical efforts to address the expensive, debilitating and dangerous problems of addiction. There is growing public awareness that social sanctions and punishments are ineffective in reducing addiction; and with growing awareness of new medications and other treatment interventions, has come public demand and a corresponding emerging marketplace that could create the economic conditions needed to promote technological innovation and commercial development of new approaches. In the US for example, the 2010 Patient Protection and Affordable Care Act appears that it will produce a dramatic change in the access and range of care options for prevention, early intervention, treatment and continuing management of substance use disorders. These are termed "essential services" in the new legislation and will be required of all healthcare organizations and health insurance plans. The implications for education and training are significant. The new legislation will expand available care from exclusively addiction specialty care providers ( 12,000 programs, $\sim 4,000$ physicians) to primary care providers ( $\sim 550,000$ physicians, $\sim 80,000$ clinical nurse practitioners). These are new responsibilities for most healthcare and social service providers and they will require considerable education and training to become competent to implement and manage effective substance misuse prevention and treatment interventions.

In summary, there are new and significant scientific, public and legislative pressures to treat addiction - and the rest of the "substance use disorders" with a public health framework. While in the US and some parts of Europe, there has been movement to provide ready access to treatment for substance use disorders, there are still considerable challenges to providing full access to prevention and treatment for substance misuse in the developing world.

\section{THE SPECIAL ISSUE}

\section{Substance Use Issues: New Insights}

Because of the global importance of substance misuse and addiction in healthcare and public health; and because of the emerging scientific, commercial and political changes in this field, this special issue of Public Health Reviews is dedicated to a comprehensive review and discussion of major areas of research that will affect—and will be affected by-new public health oriented approaches to preventing, intervening early and treating substance misuse and addiction. 
To this end we have been fortunate to enlist the support of colleagues throughout the world. They have contributed literature reviews in seven topic areas, that in combination provide a comprehensive overview of new findings and their implications; as well as insightful discussion of new issues and old controversies! We encouraged authors to describe why prevention and intervention programmes offer promise or work well, and which elements might be successfully translated into different settings or countries-especially how developing countries might make connections and learn from each other by sharing research. In the text that follows we briefly describe each of the seven articles in this Special Issue.

Rawson and colleagues ${ }^{20}$ outline the US National Institute on Drug Abuse's International Program which aims to promote dissemination of addiction science globally. This paper presents three case examples: Vietnam, Lebanon, and Abu Dhabi. Facilitative factors which help to create treatment programmes internationally include a framework of evidencebased medicine and empirical science, a receptive and supportive government, support from international donors and technical experts, networking and interest from other international organizations, and often a synergistic and concerted effort by multiple entities and partners. Despite substantial differences in the circumstances that generated these initiatives and the varying scope of the services, the paper shows that it has been possible to implement science-based treatments and systems transformations to support a public health approach to addiction.

An interesting complementary paper by Ribeiro and colleagues ${ }^{21}$ from Brazil demonstrates how that country has tackled many of the same clinical and political challenges within their health care system. The paper illustrates that while there have been significant advances in reducing tobacco use, much needs to be done with regard to alcohol and psychoactive drug use. Particularly needed is the development of more evidence based drug and alcohol related services and policies.

The paper by Schulte and Hser ${ }^{22}$ shows the importance of a "life stage" perspective in developing age-appropriate strategies to address substance use disorders and related health conditions. These investigators demonstrate that there are distinctive patterns of, and impact from use across the life course: adolescence, adulthood, and older adulthood. Only by the acknowledgement and recognition of such variations will important inroads in the understanding and treatment of the comorbid health conditions be made so as to influence overall health.

The life-stage perspective described by Schulte and Hser dovetails well with the paper by McLellan and colleagues. ${ }^{23}$ That paper offers a US 
consensus statement on how a chronic care model derived from other disorders such as diabetes might be applied to the lifetime management of substance use disorders. The chronic care model of addiction management highlights the important role of family and peer supports to enhance and sustain clinically initiated improvements in substance use. In turn, the paper by White and Evans ${ }^{24}$ continues this theme and describe the development of integrated models of peer-professional addiction recovery support. They argue that this model utilizes the strengths of both clinical and social interventions and outline how this has been achieved in the City of Philadelphia, USA.

In a more biologically oriented paper, Nutt and McLellan ${ }^{25}$ explore how more informed understanding of neuroscience may help to not only improve the effectiveness of treatment intervention but also improve the effectiveness and reduce the unintended side effects of contemporary drug policies. They suggest some rational ways neuroscience may better inform and assist in policy decisions on illegal drugs, alcohol and tobacco and the new and emerging substances-legal highs.

A particular example of this kind of approach is the fascinating article in which Pacula and Lundberg ${ }^{26}$ report that it is not possible to generate reliable estimates of the impact of liberalizing policies on either tax revenues or harms from prevalence rates, as these outcomes are most directly influenced by the amounts consumed by regular or heavy users. This is based on reviews of the economics literature by assessing the responsiveness of consumption to changes in price and enforcement risk and explicitly considers how this responsiveness varies by different user groups.

In conclusion, the editors hope that this special issue of Public Health Reviews will provoke re-examination of the pervasive, pernicious and expensive problems of substance misuse and addiction from an evidencebased public health approach. We expect that the seven synthetic examinations of important issues in this area will stimulate new clinical management efforts. However, there are important gaps in our knowledge about the most appropriate and effective options at the clinical level and at the policy level.

Nonetheless, the conclusions possible from the still meager knowledge base are quite optimistic. There is an increasing range of evidence based health promotion and treatment components and a developing willingness within the public to support new methods of prevention and treatment. The papers in this issue offer promise that the possibilities for improved prevention, treatment and management of substance use disorders have never been better. 
Acknowledgments: The writing of this paper was supported by unrestricted grants from: The National Institute on Drug Abuse, The Norlien Foundation

\section{REFERENCES}

1. Merikangas KR, McClair VL. Epidemiology of substance use disorders. Hum Genet. 2012;131:779-89.

2. Substance Abuse and Mental Health Services Administration. Results from the 2010 National Household Survey on Drug Use and Health: Summary of National Findings. NSDUH Series H-41, HHS Publication No. (SMA) 11-4658. Rockville (MD): SAMHSA; 2011. Available from URL: http:// www.samhsa.gov/data/NSDUH/2k10ResultsRev/NSDUHresultsRev2010.pdf (Accessed 17 March 2014).

3. Saitz R. Unhealthy alcohol use. N Engl J Med. 2005;352:596-607.

4. U.S. Department of Health, Education, and Welfare, Public Health Service. Smoking and Health: Report of the Advisory Committee to the Surgeon General of the Public Health Service. PHS Publication No. 1103. Washington (DC): U.S. PHS, Office of the Surgeon General; 1964. Available from URL: http://profiles.nlm.nih.gov/NN/B/B/M/Q/ (Accessed 17 March 2014).

5. World Health Organization. WHO Framework Convention on Tobacco Control. Geneva; WHO: 2003. Available from URL: http://www.who.int/fctc/text_ download/en/ (Accessed 17 March 2014).

6. Richmond R. The framework Convention on Tobacco Control: the importance of Article 14. In: Ghodse H, Hermann H, Maj M, Sartorius N, (editors). Substance Abuse Disorders. Chichester: John Wiley \& Sons, Ltd; 2011. p. 289-92.

7. McLellan AT, McKay J. Integrating evidence-based components into a functional continuum of addiction care. In: Graham AW, Schultz T, (editors). Principles of Addiction Medicine (Fourth Edition). Chicago (IL): University of Chicago Press; 2008.

8. Cherpitel CJ, Yu Y. Drug use and problem drinking associated with primary care and emergency room utilization in the US general population: data from the 2005 National Alcohol Survey. Drug Alcohol Depend. 2008;97:226-30.

9. Raven MC, Billings JC, Goldfrank LR, Manheimer ED, Gourevitch MN. Medicaid patients at high risk for frequent hospital admission: real-time identification and remediable risks. J Urban Health 2009;86:230-41.

10. Gilmer T, Hamblin A. Hospital readmissions among Medicaid beneficiaries with disabilities: identifying targets of opportunity. Faces of Medicaid Data Brief. Center for Health Care Strategies, Inc; December 2010. Available from URL: http://www.chcs.org/usr_doc/CHCS_readmission_101215b.pdf (Accessed 17 March 2014).

11. Dani JA, Harris RA. Nicotine addiction and co-moribidty with alcohol abuse and mental illness. Nat Neurosci. 2005;8:1465-70. 
12. World Health Organization. The Global Burden of Disease: 2004 Update. Geneva: WHO; 2008. Available from URL: http://www.who.int/healthinfo/ global_burden_disease/2004_report_update/en/ (Accessed 17 March 2014).

13. Frieden TR, Bloomberg MR. How to prevent 100 million deaths from tobacco. Lancet. 2007;369:1758-61.

14. United Nations Office on Drugs and Crime. World Drug Report 2007. Vienna: UNDOC; 2007. Available from URL: http://www.unodc.org/unodc/en/dataand-analysis/WDR-2007.html (Accessed 17 March 2014).

15. United Nations Office on Drugs and Crime. World Drug Report 2009. Vienna: UNDOC; 2009. Available from URL: http://www.unodc.org/documents/wdr/ WDR_2009/WDR2009_eng_web.pdf (Accessed 17 March 2014).

16. Wang PS, Angermeyer M, Borges G, Bruffaerts R, Tat Chiu W, et al. Delay and failure in treatment seeking after the first onset of mental disorders in the World Health Organization's World Mental Health Survey Initiative. World Psychiatry. 2007;6:177-85.

17. Edwards G. Alcohol Issues - what next? In: Ghodse H, Hermann H, Maj M, Sartorius N, (editors). Substance Abuse Disorders. Chichester: John Wiley \& Sons, Ltd; 2011. p. 189-92.

18. Babor TF, Caetano R, Casswell S, Grube J, Gruenewald P, et al. Alcohol: No Ordinary Commodity. Oxford: Oxford University Press; 2010.

19. Saha TD, Compton WM, Chou SP, Smith S, Ruan WJ, et al. Analyses related to the development of DSM-5 criteria for substance use related disorders: 1 . Toward amphetamine, cocaine and prescription drug use disorder continua using Item Response Theory. Drug Alcohol Depend. 2012;122:38-46.

20. Rawson RA, Rieckmann T, Gust SW. Addiction science: a rationale and tools for a public health response to drug abuse. Public Health Reviews. 2014:35; epub ahead of print.

21. Ribeiro M, Perrenoud LO, Duailibi S, Duailibi LB, Madruga C, et al. The Brazilian drug policy situation: the public health approach based on research undertaken in a developing country. Public Health Reviews. 2014:35; epub ahead of print.

22. Schulte MT, Hser Y-I. Substance use and associated health conditions throughout the lifespan. Public Health Reviews. 2014;35: epub ahead of print.

23. McLellan AT, Starrels JL, Tai B, Gordon AJ, Brown R, et al. Can substance use disorders be managed using the chronic care model? Review and recommendations from a NIDA consensus group. Public Health Reviews. 2014;34: epub ahead of print.

24. White WL, Evans AC. The recovery agenda: the shared role of peers and professionals. Public Health Reviews. 2014;35: epub ahead of print.

25. Nutt D, McLellan AT. Can neuroscience improve addiction treatment and policies? Public Health Reviews. 2014:35; epub ahead of print.

26. Pacula RL, Lundberg R. Why changes in price matter when thinking about marijuana policy: a review of the literature on the elasticity of demand. Public Health Reviews. 2014;35: epub ahead of print. 